\title{
Evaluation of the Effect of Platelet Rich Fibrin (PRF) on Bone Regeneration in the Tibia of Diabetic Rats (Histological and Immunohistochemical Studies)
}

\author{
Original \\ Article \\ El-Sakhawy, M.A. ${ }^{1}$, Sherif, $\mathrm{H}^{2}$, Abd-El Mowla, A. $^{2}$ and Dina, W. Bashir ${ }^{1}$ \\ ${ }^{I}$ Department of Cytology \& Histology, Faculty of Vet. Med. Cairo University, Egypt \\ ${ }^{2}$ Department of Oral and Dental Biology, Faculty of Dental Medicine, Boys, Cairo, \\ Al-Azhar University, Egypt
}

\begin{abstract}
Objectives: The purpose of this work was to evaluate the effect of platelet- rich fibrin (PRF) on bone defects regeneration in diabetic rats by histological studies of tibial bone and immunohistochemical examination of vascular endothelial growth factor (VEGF).

Methods:The present investigation was carried out on eighty adult male albino rats. They were divided randomly into four main groups (each of 20 rats) as the following:

Group (I): Normal control rats, received 0.9\% saline I.P. only.

Group (II): Diabetic control rats, received 0.9\% saline I.P.

Group (III): Diabetic experimental rats, received PRF.

Group (IV): Proposed group (normal control rats received PRF).

Five animals from each group were killed after 7, 14, 30 and 60 days alternatively post operatively. Diabetes was induced by injection of monohydrated alloxan. PRF was isolated from the blood of the animals in group III and IV. Bony defects were created in the tibia. The bony cavity was lifted without grafts in group I and II, while in group III and IV the bony defect received PRF. After compeletion of the experiment, the tibia was removed and the specimens were examined histologically by H\&E and Masson's trichrome stains and immunohistochemically for demonstration of "VEGF".

Results: The histological results demonstrated that there was obvious retardation in the granulation tissue and bone formation in the diabetic control group than other groups. Moreover, there was great acceleration in the bone formation in the groups treated with PRF.

Immuno-expression of the VEGF was more intense in ossifying centers, around newly formed woven bone trabeculae, in bone marrow spaces and the wall of blood vessels of diabetic and proposed groups treated with PRF.

Conclusion: The best healing and bone regeneration occurred in the groups treated with PRF which was markedly increased along the intervals of the study.
\end{abstract}

Received: 30 October 2019, Accepted: 12 November 2019

Key Words: Bone regeneration, diabetic rats, platelet rich fibrin, VEGF and.

Corresponding Author: Dina, W. Bashir, PhD, Cytology and Histology Department, Faculty of Veterinary Medicine, Cairo University, Cairo, Egypt, Tel.: +202 22021035, E-mail: dr_dina50@yahoo.com

ISSN: $1110-0559$, Vol. 43, No.3

\section{INTRODUCTION}

One of the major problems in many medical and dental specialties is bone loss. During the healing, certain problems may occur as infection, clot destruction, dehiscence in addition to pathologic fracture ${ }^{[1]}$. Multiple etiologies cause diabetes mellitus which is a metabolic disorder characterized by chronic hyperglycemia with impairment of carbohydrate, fat, protein and electrolytes metabolism. It occurs due to defects in insulin secretion or action or both ${ }^{[2]}$. Diabetes causes diminished bone formation and increases the risk of fracture ${ }^{[3,4]}$. Microvascular complications of diabetes and reduced blood flow, in addition reduced osteoblastic activity and bone mineralization lead to increase bone fragility ${ }^{[5,6]}$.
Thus, healing in diabetic patients is a problem with major and minor surgeries. The healing of soft and hard tissues is mediated by a wide range of intra and extracellular events that are regulated by signaling proteins. Platelets play a definitive role not only in hemostasis, but also in wound healing process ${ }^{[7]}$. Platelet rich fibrin (PRF) belongs to a group of second generation blood autologous preparations that was originally described by ${ }^{[8]}$. PRF is a rich source of autologous cytokines and growth factors in addition, it considered as a new biomaterial in clinical application $^{[9]}$. PRF is a biocompatible, biodegradable, three dimensional polymerized fibrin meshwork in which the platelet, leukocytes, cytokines (interleukin-1b (IL-1b), IL-4 and tumor necrosis factor $\alpha$ ), growth factors such as 
(transforming growth factor $-\beta 1$ (TGF- $\beta 1$ ), platelet derived growth factor (PDGF), vascular endothelial growth factor (VEGF), insulin like growth factor1 (IGF1), matrix glycoproteins such as (thrombospondin-1, fibronectin and vitronectin) are trapped and may be delivered for a certain time to play an essential role in wound repair. Also, it provides a matrix for migration of tissue-forming cells like fibroblasts and endothelial cells, which are involved in angiogenesis and are responsible for re-modeling of the new tissue ${ }^{[10]}$.

VEGF is a signal protein produced by cells that stimulate angiogenesis ${ }^{[11]}$.

The main goal of this study is to perform histological and immunohistochemical evaluation on the effect of PRF on bone regeneration in bone defects in the tibia of diabetic rats.

\section{MATERIALS AND METHODS}

\section{Experimental Animals}

Eighty adult male albino rats (Rattus albinos) were used in this study, with an average age of 2.5 months old, and weight of approximately $250 \mathrm{gm}$. The animals were housed in a controlled environment with good ventilation condition in the animal house of biochemical department, Faculty of Medicine, Al Azhar University. Throughout the experiment, the animals were given regular stander rat chow and water ad libitum. Medical and health care of the experimental rats were maintained all over the experimental period.

All animals procedures were performed in accordance with the ethics committee of the faculty of dentistry, $\mathrm{Al}$ Azhar University.

\section{Study Design}

The rats were divided randomly into four main groups (each of 20 rats) as the following:

Group (I): Normal control group, received $0.9 \%$ saline I.P. only.

Group (II): Diabetic control group, received 0.9\% saline I.P.

Group (III): Diabetic experimental group, received PRF PRF).

Group (IV): Proposed group (normal control received

\section{Induction of Diabetes}

Diabetes was induced by a single intraperitoneal injection of $120 \mathrm{mg} / \mathrm{kg}$ monohydrated alloxan (Sigma, St. Louis, MO) dissolved in sterile $0.9 \%$ saline. Rats were fasted before alloxan administration. After 12 hours, a 10\% glucose solution was offered to the animals to prevent hypoglycemia. After 7 days, blood samples were collected from the caudal vein of the rats for evaluation of plasma glucose levels. The animals that presented glycemic levels higher than $250 \mathrm{mg} / \mathrm{dL}$ were considered diabetic and used in the current study.

All animals were submitted to blood collection via caudal vein for evaluation of plasma glucose level by the glucose-oxidase enzymatic method using a glucometer (Glucometer Accu-Check, Roche, Mannheim, Germany) and commercially available glucostix reagent strips.

\section{Preparation of PRF}

PRF was isolated from the blood of the animals in group III and IV as the following:

Approximately $3.5 \mathrm{ml}$ of blood was drawn from the caudal vein of the rat. The blood was then placed in $5 \mathrm{ml}$ tubes and centrifuged immediately, only once, without anticoagulant, for $10 \mathrm{~min}$. at speeds of $3000 \mathrm{rpm}$ as recommended by ${ }^{[12]}$. The PRF located in the middle portion of the tube was isolated from the remaining blood components by clamping.

\section{Surgical Procedures}

A course of antibiotic was began one day preoperatively by injecting Keflex (cephalexin monohydrate), (15 mg/kg, IM, q24 hrs. $)^{[13]}$. Food and water were kept away from the animals 12 hours prior to the operation to prepare them for anesthesia.

The animals were weighed, premedicated by atropine (IM $0.04 \mathrm{mg} / \mathrm{kg}$ ) and anaesthetized intramuscularly with a combination of $2 \%$ xylazine in a dose of $5 \mathrm{mg} / \mathrm{kg}$ (ADWIA, Egypt) and Ketamine in a dose of $50 \mathrm{mg} / \mathrm{kg}$ (ROTEXMEDICA, Germany). The overlying skin of the tibia was shaved and disinfected with iodate alcohol. An incision about $2 \mathrm{~cm}$ was then made in the medial aspect of the tibia, full thickness flap, the skin, subcutaneous tissue and muscular layer were reflected exposing the tibial bone. A circular 5-mm diameter defect created using carbide rose head surgical bur mounted in a dental hand piece connected to a micro- motor with $2000 \mathrm{rpm}$ speed, a metal template with a round cavity $5 \mathrm{~mm}$ in diameter had been used to standardize the defect site and size. The process of defect creation was done under copious irrigation with warm saline to avoid bone burning and to maintain the vitality of bone cells around the defect.

In group (I) and group (II) the defect was left without PRF while in group (III) and (IV) PRF was placed in the defect, then the flap was repositioned, the muscular layer was sutured with resorbable \# 4.0 catgut and the skin was sutured with interrupted \# 4.0 silk sutures.

\section{Postoperative Care}

When the operative procedures were completed, animals were injected with meloxicam $(1.0 \mathrm{mg} / \mathrm{kg}$, IM, q 24 $\mathrm{hrs}$ ) as analgesic for 3 days post-surgery ${ }^{[14]}$. Also, they were injected with Keflex (cephalexin monohydrate) every 24 hours (15mg/kg, IM, q $24 \mathrm{hrs}$ ) for 7 days postoperatively ${ }^{[13]}$. Rats were kept on their usual diet. 


\section{Animals Grouping and Killing}

The eighty animals used in this study were divided equally into 4 groups, twenty rat in each group. Animals were humanly killed after 7, 14,30 and 60 days alternatively post operatively.

\section{Assessment of Bone Regeneration}

Bone regeneration at the area of bone defect was assessed histologically by using haematoxylin and eosin stain and Masson 's trichrome stain for paraffin sections ${ }^{[15]}$.

\section{Immunohistochemical Examination of VEGF}

Sections were deparaffinized with xylene, hydrated in a series of descending grades of alcohol, and then rinsed briefly with tap water and phosphate buffered saline (PBS) (pH 7.4). They were incubated in $0.3 \% \mathrm{H}_{2} \mathrm{O}_{2}$ in methanol for $10 \mathrm{~min}$. Nonspecific protein binding was blocked with normal serum for $10 \mathrm{~min}$. For the primary antibodies, the sections were incubated for $12 \mathrm{hrs}$ at $4^{\circ} \mathrm{C}$ with polyclonal (anti vascular endothelial growth factor, Santa Cruz Biotechnology, Santa Cruz, CA, USA). They were then rinsed with PBS three times for 5 min each time and incubated with biotinylated secondary antibodies for 10 min and with streptavidin-enzyme conjugate solution for 5 $\min$. The antibody-localized antigen was then detected by peroxidase activation of 3,3'-diaminobenzidine for $10 \mathrm{~min}$ to give it brownish discoloration. Finally, the sections were counterstained lightly with hematoxylin ${ }^{[16]}$.

\section{Evaluation of Immunohistochemical Observations}

Immunohistochemically stained sections were examined using Leica Quin 500 analyser computer system (Leica Microsystems, Switzerland) in Faculty of Dentisty, Cairo University. The image analyser was calibrated automatically to convert the measurement units (pixels) produced by the image analyser program into actual micrometer units. Immunohistochemical reactions were measured as area percent in standard measuring frame in 5 fields from different slides in each group using magnification (X400) by light microscopy transferred to the monitor's screen. The areas showing the positive immunohistochemical reaction were chosen for evaluation, regardless the intensity of the staining. These areas were masked by a blue binary colour to be measured by the computer system. Mean value and standard deviation were obtained for each specimen and statistically analysed

\section{Statistical Analysis}

Data related to the area percent were presented as mean and standard deviation (SD) values. ANOVA one way test was used to determine statistical significance $(P \leq 0.05)$ among the different groups. Calculations were performed using statistical package for social science (SPSS) software version 16 package for windows.

\section{RESULTS}

\section{A. Histological Results}

\section{I- Seven Days Intervals}

Seven days intervals of normal control group demonstrated that the center of the defect was filled with remnant of blood clot which infiltrated by inflammatory cells: macrophages, fibroblasts and BV. Well organized granulation tissues were observed underneath the blood clot which characterized by more condensed, tightly packed collagen bundles interspersed by fibroblasts, inflammatory cells and proliferating blood capillaries. Sequestrated bones were noticed within the granulation tissues and surrounded by osteoclasts. At the sides of the defect, there were osteoclasts located on bays like depression within the old bone (Figure 1A).

The diabetic control group at seven days intervals showed remnant of blood clot fills the center of the defect and infiltrated by inflammatory cells, macrophages, fibroblasts and blood vessels (BV). The blood clot still replaced by early formation of granulation tissue. A reversal line was seen at the sides of the defect (Figure 1B).

Seven days intervals of diabetic group treated with PRF demonstrated that the center of the defect was filled with remnant of PRF meshwork which infiltrated by inflammatory cells and macrophages. It was surrounded by blood clot which still replaced by early granulation tissue formation. Well organized granulation tissues were observed underneath the PRF meshwork and the blood clot. They were characterized by more condensed, tightly packed collagen bundles which interspersed by fibroblasts and proliferating blood capillaries and there were wide sinusoidal spaces. Also, there was a proliferation of wellorganized granulation tissues overhanging the edge of the defect. A well demarcated scalloped reversal line was seen at the sides of the defect and osteoclasts located on bays like depression distributed along the reversal line (Figure 1C). At the base and sides of the defect there were early formation of new bone trabeculae which was lined by osteogenic cells and osteoblasts. There were osteoblasts imprisoned within the bone matrix of the newly formed bone forming osteocytes with wide osteocytic spaces (Figure 1D).

The normal control group treated with PRF at seven days intervals showed that meshwork of PRF remnants fill the center of the defect. This PRF meshwork was infiltrated by inflammatory cells and macrophages. There were well organized granulation tissue underneath the meshwork, characterized by more condensed, lightly packed collagen bundles which interspersed by fibroblasts and proliferating blood capillaries with presence of wide sinusoidal spaces (Figure 1E). Recruitment of osteoblasts was observed within the granulation tissue (Figure 1F). 
At the base and sides of the defect there were new bone trabeculae formation enclosing marrow spaces containing haemopiotic tissues. The side of the defect demonstrated well demarcated scalloped reversal line and osteoclasts located on bays like depression (Figures. 1E and 1F).

\section{II- Fourteen Days Intervals}

The normal control group at fourteen days intervals showed thin rim of typically organized granulation tissues with tightly packed collagen bundles and proliferating blood vessels at the center of the defect. At the base and sides of the defect there was new woven bone formation as thin irregular bone trabeculae which dispersed away from each other and lined by osteogenic cells and osteoblasts. Well demarcated scalloped reversal line separating the newly formed bone trabeculae from the old bone with osteoclasts located on bays like depression distributed along the reversal line (Figure 2A).

Fourteen days intervals of diabetic control group demonstrated remnant of blood clot fill the center of the defect which still replaced by granulation tissue. The granulation tissues showed recruitment of osteoblasts along the surface of the newly formed bone. At the base and sides of the defect there was early formation of new woven bone which formed of thin irregular bone lamellae and trabeculae. The new bone trabeculae revealed early formation of very wide irregular marrow sinusoidal haemopiotic cavities filled with haemopiotic tissue and begin to connect to the old bone to form bridge to protect the injured haemopiotic tissue. Well demarcated scalloped reversal line separated the newly formed bone from the old one at the sides of the defect (Figures 2B and 2C).

The diabetic group treated with PRF at fourteen days intervals showed the center of the defect was filled with remnant of PRF which infiltrated by inflammatory cells and macrophages. It was surrounded by typically organized granulation tissues. At the base and sides of the defect there was new formation of bone trabeculae of variable thickness and coalescent and anastomosed with each other as initial stage of cancellous bone formation. The bone trabeculae were lined by osteoblasts and osteoprogenitor cells. In between the newly formed bone trabecula, there were wide marrow sinusoidal haemopiotic cavities with variable diameters filled with haemopiotic tissue (Figure 2D). There was over hanging chondroid bone or woven bone with multiple osteocytes imprisoned within its matrix at the periphery of the defect (Figures 2D and 2E).

Fourteen days intervals of the normal group treated with PRF demonstrated remnant of PRF at the center of the defect surrounded by typically organized granulation tissues. There was new formation of bone trabeculae of variable thickness at the base and sides of the defect which coalescent and anastomosed with each other as initial stage of spongy bone formation. In between the newly formed bone trabeculae, there were wide marrow sinusoidal haemopiotic cavities filled with haemopiotic tissue. At the periphery of the defect there were over hanging chondroid bone. (Figure 2F)

\section{III- Thirty Days Intervals}

Thirty days intervals of normal control group demonstrated small remnant of blood clot at the surface of the defect which still replaced by area of typically organized granulation tissue with tightly packed collagen bundles, bone spicules and recruitment of osteoblasts. At the center of the defect there was new bone characterized by thin irregular bone trabeculae which mostly dispersed away from each other (Figure 3A). Bone trabeculae were lined by osteogenic cells and osteoblasts and harboring wide irregular marrow sinusoidal haemopiotic cavities in between them. A reversal line was demarcating the old bone from the newly formed one at the periphery of the defect (Figure 3B).

Diabetic control group at thirty days intervals showed at the surface of the defect there was thin rim of well-organized granulation tissues with tightly packed collagen bundles with bone spicules and recruitment of osteoblasts. Thin irregular trabeculae of woven bone were dispersed away from each other filling the center of the defect (Figure 3C). The retardation of the healing process appeared in term of decreased thickness, size and number of bone trabeculae.

Thirty days intervals of diabetic group treated with PRF demonstrated remnant of PRF underneath thin rim of typically organized granulation tissues with mature collagen bundles. Moreover, bone spicules were formed in and around these collagen bundles (Figure 3D). There was chondroid bone formation overhanging the edge of the defect with multiple osteocytes imprisoned within its matrix (Figure 3E).

The normal control group treated with PRF at thirty days intervals showed small remnants of PRF surrounded by granulation tissue with heavy formation of bony spicules and recruitment of osteoblasts. New cancellous bone formed of thick bone trabeculae fill the center of the defect. These trabeculae anastomosed with each other forming bone islands and harboring marrow cavities filled with haemopiotic tissue. These marrow cavities become narrower as initial stage of osteon formation. There was chondroid bone formation over hanging the edge of the defect (Figure 3F).

\section{IV-Sixty Days Intervals}

Normal control group at sixty days intervals showed healing of the defect by new bone formation which connected with the old bone. The surface of the defect was healed by spongy bone which still converted to osteonal bone by narrowing of marrow cavities and formation of primary and secondary osteons. Cancellous bone filled the center of the defect (Figure 4A). Many reversal lines in the newly formed bone denoted active remodeling of cancellous bone to be replaced by osteonal bone. In addition, reversal lines demarcated the old bone from the newly formed one (Figure 4B). 
Sixty days intervals of diabetic control group demonstrated that the defect was healed by new bone formation which connecting the old bone. The surface of the defect was healed by cancellous bone which starts to be converted to osteonal bone by narrowing of the marrow cavities and formation of primary osteons in some areas. While the center of the defect was filled with islands of cancellous bone which harboring wide irregular marrow cavities filled with haemopiotic tissue and lined with osteogenic cells and osteoblasts (Figure 4C).

Diabetic group treated with PRF at sixty days intervals showed that the defect was healed at the surface by rim of osteonal bone in different degrees of maturation which formed of primary and secondary osteons. Each osteon composed of concentric bony lamellae enclosing central haversian canals housing blood vessels. Few islands of spongy bone still present inside the wide marrow cavity and demonstrate formation of primary osteon (Figure 4D). The newly formed osteonal bone appeared to be perpendicular to the old one.

Sixty days intervals of the normal group treated with PRF demonstrated that the defect was healed by new osteonal bone characterized by formation of primary and secondary osteons. Many reversal lines denoted active remodeling of osteon to be converted to mature osteon. At the center of the defect marrow cavity spaces filled with haemopiotic tissues. There were few islands of cancellous bone still present within these cavities and reveal formation of primary osteons. Reversal lines demarcated the old bone from the newly formed one (Figure 4E).

\section{B. Immunohistochemical Results of VEGF}

The immunoreactivity of the "VEGF" was weak in ossifying centers, around newly formed woven bone trabeculae, in bone marrow spaces and wall of blood vessels of the normal control group in all intervals (Figure 5A).

Moderate immunoexpression of VEGF in the diabetic control group (Figure 5B) and more intense in the diabetic and proposed groups treated with PRF in all intervals studied (Figures 5C and 5D).

\section{Evaluation of Immunohistochemical Results of VEGF}

ANOVA test showed a significant difference $(\mathrm{p}=0.0000)$ in area percent values when comparing the four groups together. Group IV then III showed the greatest values followed by group II and group I which showed the least value (Table 1 and Figure 6).

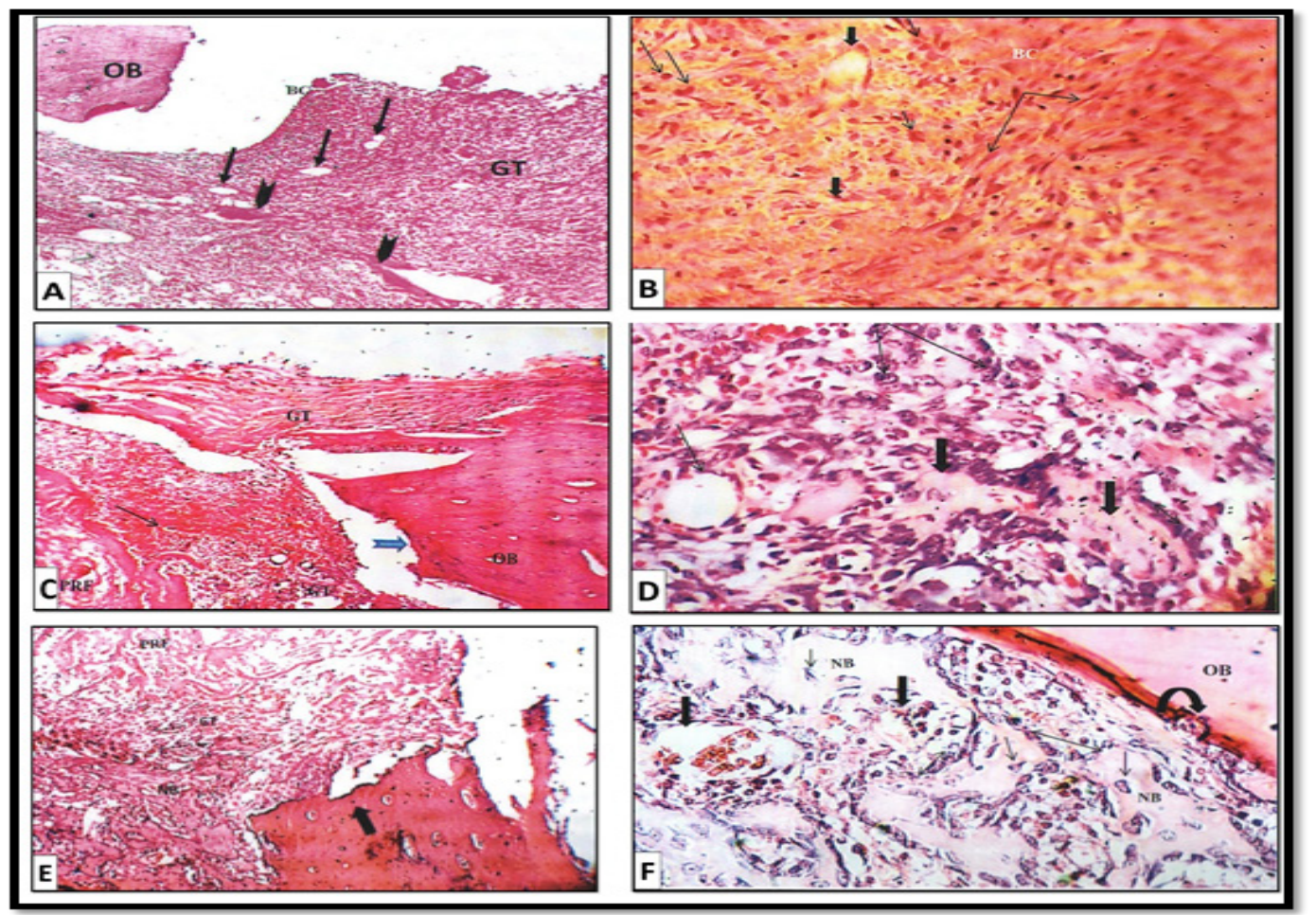

Fig. 1: (A:F): Sections of male albino rat tibia at 7 days interval (A) Normal control group showing remnant of blood clot (BC), well organized granulation tissue (GT), blood vessels (arrows), sequestrum (arrow heads) and old cortical bone (OB). H\&E X100. (B) Diabetic control group showing blood clot (BC) replaced by granulation tissue, collagen fibers with fibroblasts (double arrows), blood vessels (thick arrows) and inflammatory cells (thin arrows). H\&E X400. (C) Diabetic group treated with PRF showing remnant of (PRF), well organized granulation tissue (GT), remnant of blood clot (thin arrow) and edge of the defect (OB) showing osteoclastic activity (blue arrow). H\&E X100. (D) Diabetic group treated with PRF showing osteocytes imprisoned in the newly formed bone trabeculae (thick arrows), surface osteoblasts (double head arrow), wide sinusoidal space (thin arrow) and inflammatory cells (double arrow). H\&E X 400. (E) Normal control group treated with PRF showing remnant of PRF, well organized granulation tissue (GT), new woven bone (NB), edge of the defect showing osteoclastic activity (thick arrow). H\&E X100. (F) Normal control group treated with PRF showing old bone (OB),osteoclast laying on its resorptive lacunae (curved arrow), osteocytes (thin arrow), impresond in the newly formed bone trabeculae (NB), surface osteoblasts (double head arrow), early sinusoida space filled with haemopiotic tissue (thick arrow). H\&E X400. 


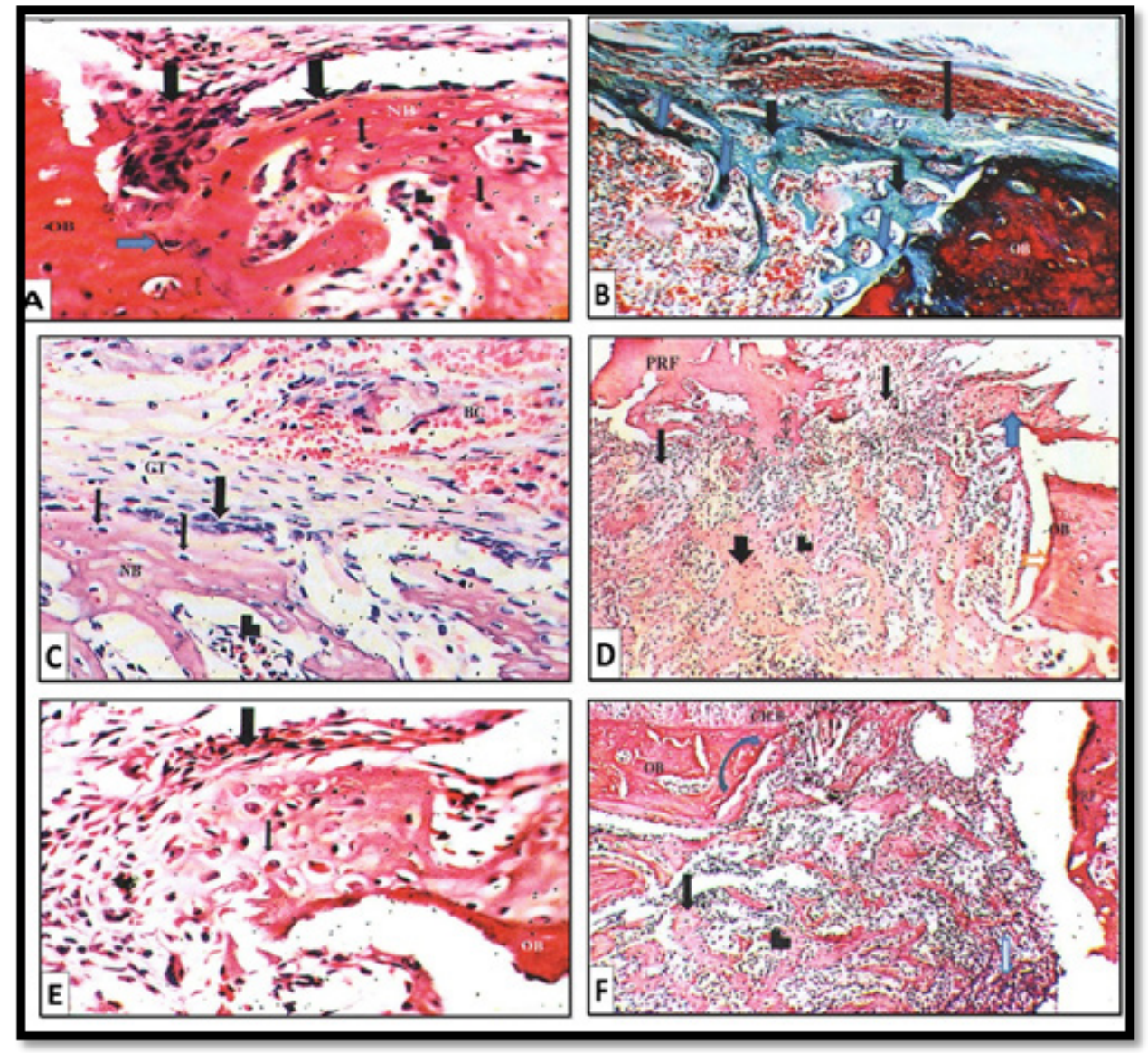

Fig. 2: (A:F): Sections of male albino rat tibia at 14 days interval (A) Normal control group showing well organized collagen bundles with fibroblasts (GT), irregular trabeculae of new woven bone (NB), osteocytes with wide osteocytic space (thin arrows), recruitment of osteoblasts (thick arrows), marrow cavity with haemopiotic tissue (arrow head), old bone (OB) and reversal line with osteoblasts activity (blue arrow). H\&E X400. (B) Diabetic control group showing remnant of blood clot replaced by granulation tissues indicated by light green colour (thin arrow), well organized collagen bundles indicated by blue colour (thick arrows) with spotty areas of mineralization indicated by red colour (blue arrows). Masson's trichrome X100. (C) Diabetic control group showing remnant of blood clot (BC), well organized granulation tissue (GT), recruitment of osteoblasts (thick arrow), thin irregular trabeculae of new woven bone (NB), osteocytes with wide osteocytic space (thin arrows) and marrow cavity with haemopiotic tissue (arrow head). H\&E X400. (D) Diabetic group treated with PRF showing remnant of PRF infiltrated by macrophages (double head arrows), well organized granulation tissue (thin arrows), trabeculae of woven bone (thick arrow), marrow cavity with haemopiotic tissue (arrow head), reversal line showing osteoclastic activity (yellow arrow), chondroid bone (blue arrow) and old bone (OB). H\&E X100. (E) Diabetic group treated with PRF showing overhanging chondroid bone or woven bone with multiple osteocytes imprisoned within its matrix forming hyaline cartilage (thin arrow) and recruitment of osteoblasts (thick arrow). H\&E X400. (F) Normal control group treated with PRF showing remnant of PRF, well organized granulation tissue (thin arrow), recruitment of osteoblasts (blue arrow), thick trabeculae of woven bone (thick arrow), marrow cavity with haemopiotic tissue ( arrow head), old bone (OB), reversal line with multiple osteoclasts (curved arrow) and chondroid bone (Ch.B). H\&E X100 

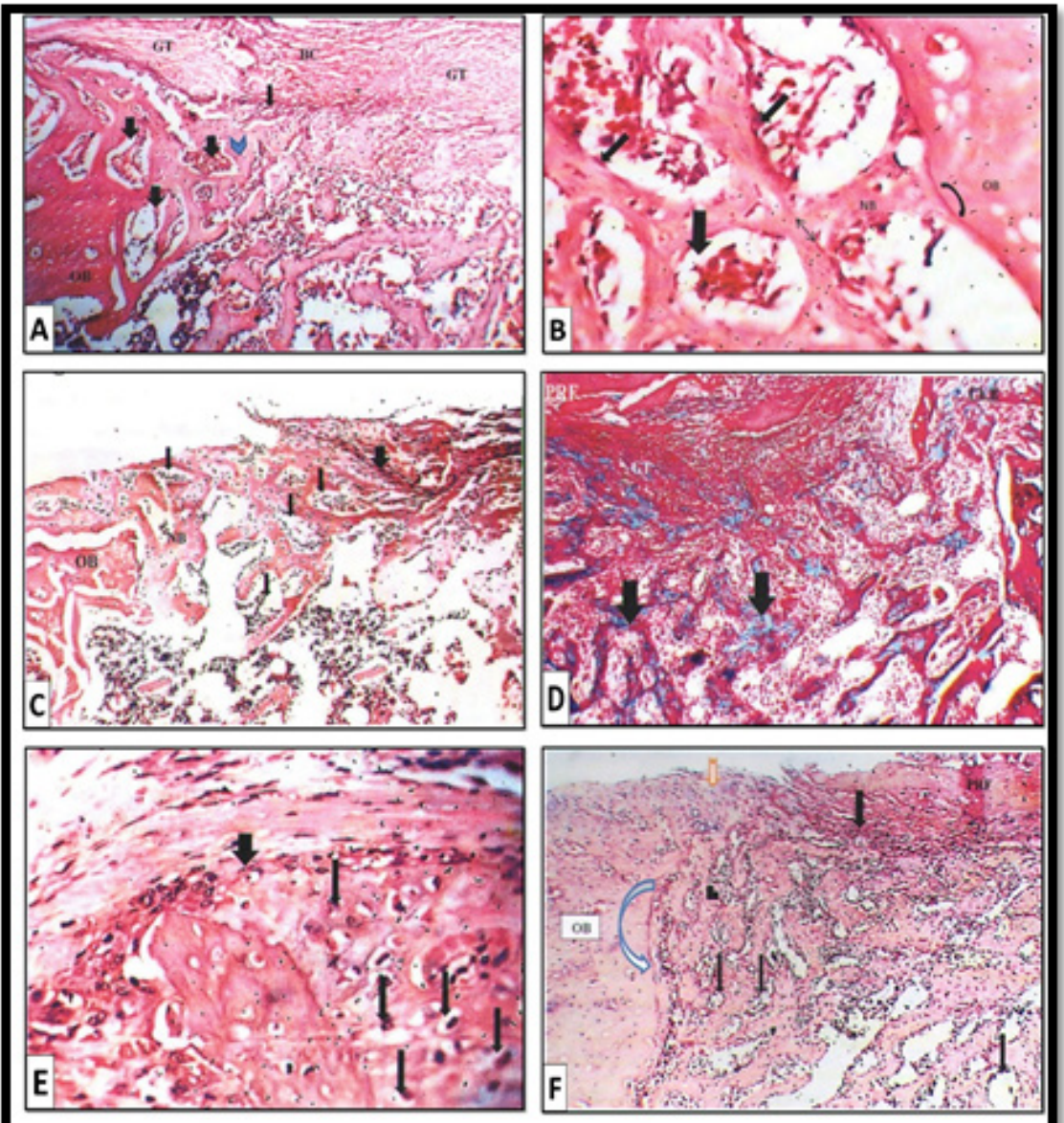

Fig. 3: (A-F): ): Sections of male albino rat tibia at 30 days interval (A) Normal control group showing small remnant of blood clot (BC), organized granulation tissue (GT), recruitment of osteoblasts (thin arrow), trabeculae of cancellous bone (arrow head), marrow sinusoidal haemopiotic cavities (thick arrows) and old bone (OB). H\&E X100. (B) Normal control group showing trabecular network of the new bone (NB), osteocytes (double head arrow), marrow sinusoidal haemopiotic cavities (thick arrow) lined by osteoblasts and osteogenic cells (thin arrows), reversal line (curved arrow) and old bone (OB). H\&E X400. (C) Diabetic control group showing thin rim of well organized granulation tissue (GT), recruitment of osteoblasts (thick arrow), thin trabeculae of woven bone which dispersed away from each other (NB), wide irregular marrow sinusoidal haemopiotic spaces (thin arrows) and old bone (OB). H\&E X100. (D) Diabetic group treated with PRF showing remnant of (PRF) underneath thin rim of typically organized granulation tissue with mature collagen bundles indicated by blue colour and bony spicules indicated by red colour (GT), newly formed bone trabeculae in different degree of mineralization ranging from red to purple colour (thick arrows) and chondroid bone (Ch.B). Masson's trichrome. X100. (E) Diabetic group treated with PRF showing chondroid bone formation which overhanging the edge of the defect with multiple osteocytes imprisoned within its matrix (thin arrows) and recruitment of osteoblasts (thick arrow). H\&E X400. (F) Normal control group treated with PRF showing small remnant of PRF, well organized granulation tissue (thick arrow), thick trabeculae of cancellous bone (arrow head), marrow space (thin arrow), chondroid bone (yellow arrow), old bone (OB) and reversal line (curved arrow). H\&E X100. 


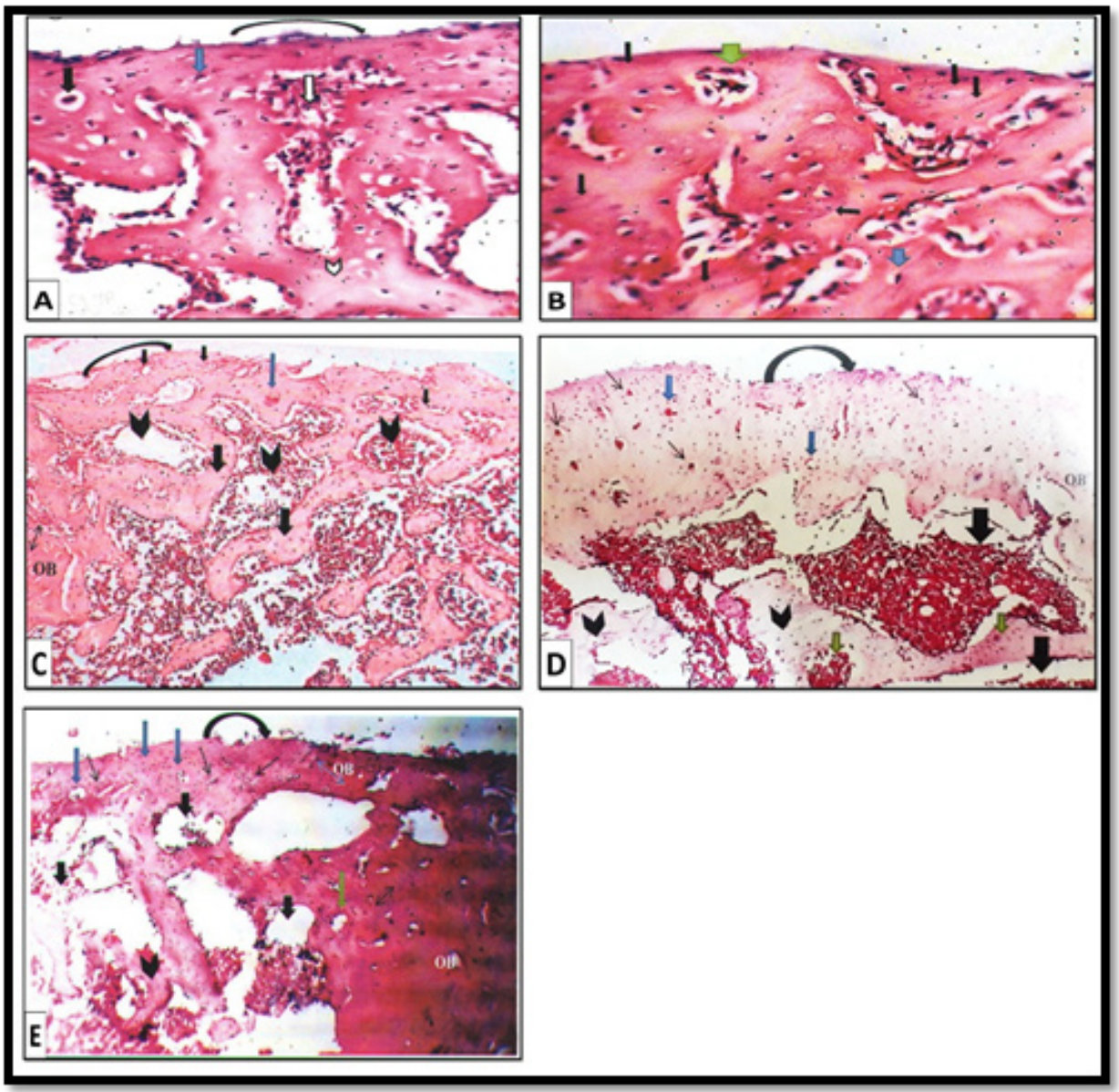

Fig. 4: (A:E) Sections of male albino rat tibia at 60 days interval (A) Normal control group showing early stage of osteonal bone formation (curved arrow), primary osteons (blue arrow), secondary osteon (black arrow), trabeculae of cancellous bone (arrow head) and wide marrow cavities start to be marrow lined by osteogenic cells and filled with haemopiotic tissue (white arrow). H\&E X400. (B) Normal control group showing active remodeling of the spongy bone, many reversal lines (thin arrows), trabeculae of cancellous bone (blue arrow) and narrowing of marrow cavities to form osteon (green arrow). H\&E X400. (C) Diabetic control group showing layer of spongy bone at the surface of the defect start toconvert to osteonal bone (curved arrow), narrow marrow cavities (thin arrows), primary osteon (blue arrow), islands of spongy bone in the center of the defect (thick arrows), wide irregular marrow cavities filled with haemopiotic tissue and lined by osteogenic and osteoblasts (arrow heads) and reversal line (double head arrow). H\&E X100. (D) Diabetic group treated with PRF showing new osteonal bone (curved arrow), primary osteon (thin arrows), secondary osteon (blue arrows), islands of cancellous bone (arrow heads), large marrow cavities lined by osteogenic cells and filled with haemopiotic tissue (thick arrows) and osteon formation within the spongy bone (green arrows). H\&E X100. (E) Normal control group treated with PRF showing new osteonal bone (curved arrow), primary osteon (thin arrows), secondary osteon (blue arrows), reversal line (double head arrow), islands of cancellous bone (arrow head), large marrow cavities lined by osteogenic cells and filled with haemopiotic tissue (thick arrow) and osteon formation within the spongy bone (green arrows). H\&E X100. 


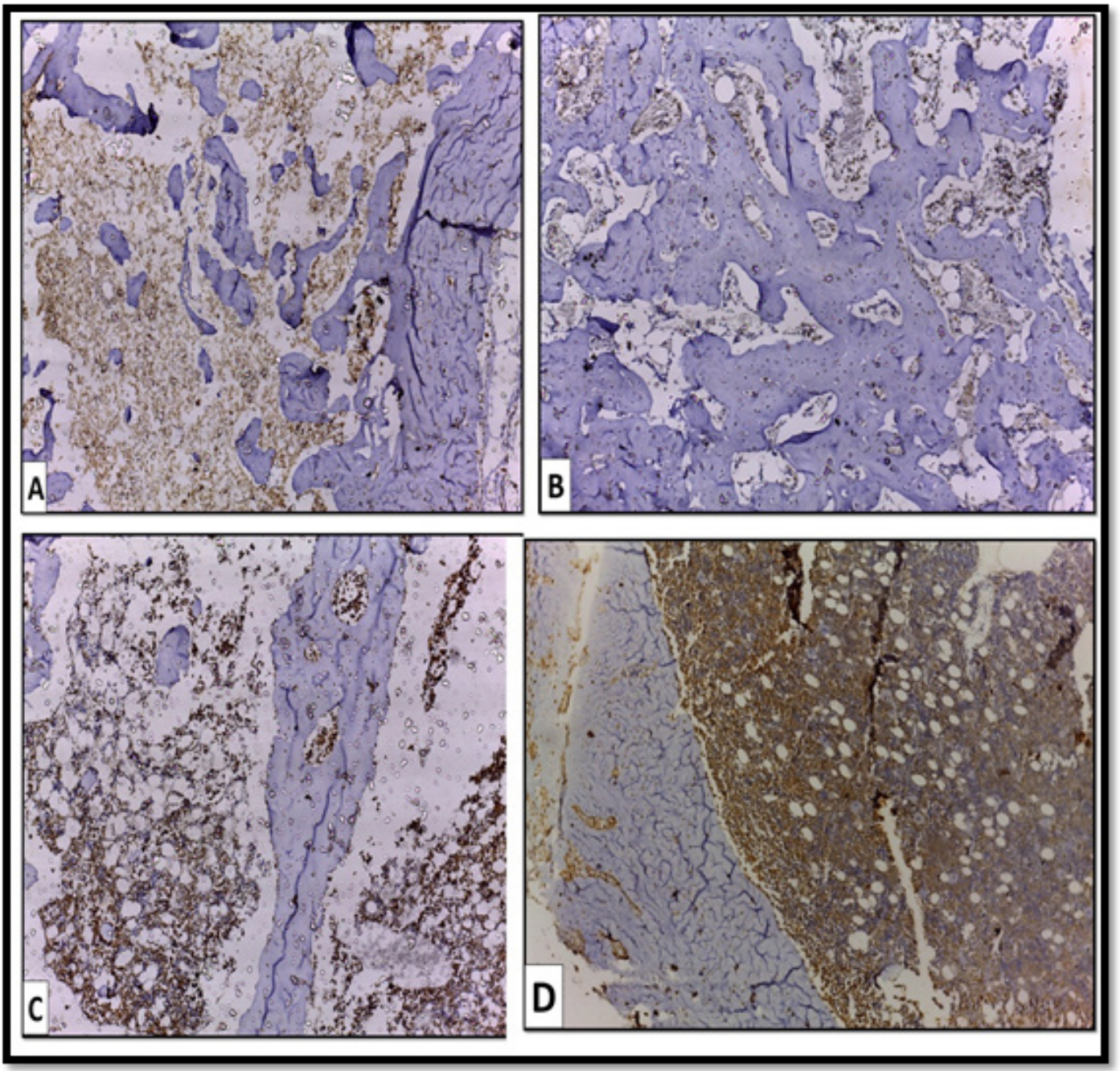

Fig. 5: Sections of male albino rat tibia at 60 days interval (A) Normal control group showing weak immunoreactivity of the vascular endothelial growth factors "VEGF". X100. (B) Diabetic control group showing moderate immune reaction of "VEGF". X100. (C) Diabetic group treated with PRF showing intense immunoexpression of "VEGF" especially in bone marrow and wall of blood capillaries. X100. (D) Normal control group treated with PRF showing intense immunoexpression of "VEGF" especially in bone marrow. X100.

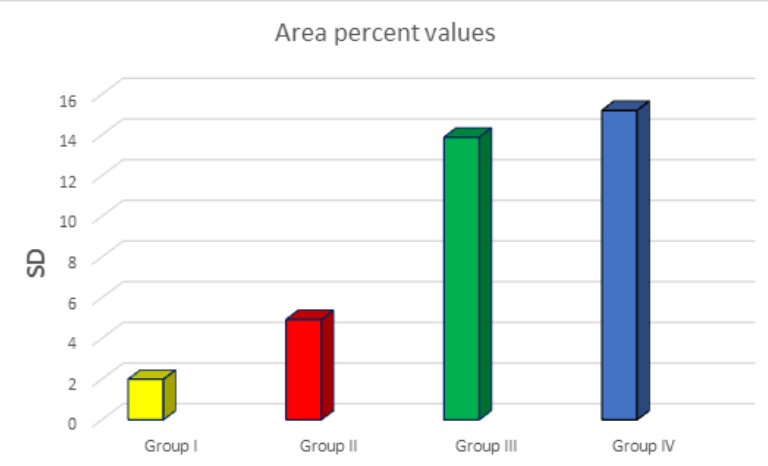

Fig. 6: Area percent values of VEGF for the four studied groups

Table 1: Comparing area percent values of VEGF for the four studied groups (ANOVA test)

\begin{tabular}{lccccc}
\hline & Group I & Group II & Group III & Group IV & $P$ value \\
\hline Mean +SD & $1.99+0.53$ & $4.93+1.98$ & $13.89+3.32$ & $15.21+2.12$ & $\mathrm{P}=0.0000^{*}$ \\
\hline
\end{tabular}

$P$ values $<0.05$ are significant $\quad P$ values $<0.001$ are highly signifcant 


\section{DISCUSSION}

Diabetes has a great effect on bone healing as it is one of the most important sugar metabolic disorders. It is associated with poor osseous healing, bone resorption and impaired bone regeneration ${ }^{[17,18]}$. To normalize the healing process, supplementing wound sites with growth factors provided by other means seems to be a viable alternative ${ }^{[19]}$.

PRF is a biodegradable, biocompatible and three dimensionally polymerized fibrin meshwork. The platelet, leukocytes, cytokines, growth factors and matrix glycoproteins are trapped in the PRF and delivered for certain time to play an essential role in wound repair. The tissue forming cells like fibroblasts and endothelial cells which are involved in angiogenesis and are responsible for remodeling of the new tissue are migrated through the matrix provided by $\mathrm{PRF}^{[10]}$.

The current work revealed that, in the normal control group at seven days interval the bone defect was filled with remnant of blood clot which still replaced by early formation of granulation tissues. The collagen bundles were interspersed by fibroblasts, blood vessels and few bony spicules. These findings are in agreement with ${ }^{[20,21]}$ who stated that the clot is replaced by granulation tissue by cellular mobilization and vascular in growth with extensive neo-angiogenesis mediated by different VEGFs.

The diabetic control group at seven days interval showed that the center of the defect was filled with blood clot which still replaced by early formation of granulation tissue with no bone spicules formation. These observations come in contact with the findings of ${ }^{22,23]}$ who stated that diabetes reduce cellular proliferation in early callus and reduce collagen synthesis content.

Moreover, the diabetic group treated with PRF at seven days interval revealed that the center of the defect was filled with remnant of PRF meshwork. Well organized granulation tissues were observed underneath the PRF meshwork. These results are in parallel to the findings of $^{[24]}$ who stated that PRF aid in tissue regeneration by acting as a scaffold for the undifferentiated mesenchymal cells that facilitate the differentiation of these cells.

In the normal control group treated with PRF at seven days intervals, the center of the defect was filled with remnant of PRF. There was well organized granulation tissue underneath the PRF. Also, at the base and sides of the defect there was formation of new bone trabeculae. These findings are coincidental with the results of ${ }^{[25,26]}$. Stated that PRF accelerate early bone regeneration by angiogenesis, chemotaxis, mitosis and stem cell proliferation as it contains numerous growth factors such as PDGF,TGF-B and IGF.

The authors of this work observed from the different histological findings between the groups at seven days interval, PRF played an important role in acceleration of granulation tissue formation and maturation of its collagen bundles. In addition, PRF accelerated woven bone formation. On the other hand, there was retardation in granulation tissue formation and maturation of its collagen bundles in the diabetic control group due to decreased growth factors.

The present study at fourteen days interval demonstrated obvious histological differences among the three groups of this study.

The current investigation revealed that, the normal control group at fourteen days intervals showed thin rim of typically organized granulation tissues with tightly packed collagen bundles and proliferating blood vessels at the center of the defect. At the base and sides of the defect there was new woven bone formation as thin irregular bone trabeculae. Well demarcated scalloped reversal line separating the newly formed bone trabeculae from the old one was also seen.

The diabetic control group at fourteen days interval demonstrated remnant blood clot filling the center of the defect which still replaced by granulation tissue. At the base and sides of the defect there was early formation of new woven bone. These findings were in coincidental with ${ }^{[23,27,28]}$ who postulated that diabetes leads to decreased cellular proliferation, chondrocyte proliferation and differentiation, impairment of collagen and extracellular matrix production and new blood vessels formation.

On the other side, the diabetic group treated with PRF at fourteen days interval showed the center of the defect filled with remnant of PRF which surrounded by typically organized granulation tissues. At the base and sides of the defect there was new formation of bone trabeculae of variable thickness and coalescent and anastomosed with each other as initial stage of spongy bone formation. These findings are in parallel with the work of ${ }^{[29]}$ who stated that PRF provide a fibrin scaffold that allows cellular migration. Furthermore, it is able to stimulate osteogenesis in bone environment in addition to angiogenesis.

At fourteen days intervals, the normal group treated with PRF demonstrated remnant of PRF at the center of the defect surrounded by typically organized granulation tissues. At the base and sides of the defect there was new formation of bone trabeculae of variable thickness which anastomosed with each other as initial stage of spongy bone formation. There were wide marrow sinusoidal haemopiotic cavities in between the newly formed bone trabeculae, filled with haemopiotic tissue. At the periphery of the defect there were over hanging chondroid bone. These findings are in agreement with ${ }^{[30]}$ who stated that bone morphogenic proteins enmeshed in fibrin matrix of PRF have the ability to be released consistently highlighting the angiogenic, hemostatic and osteoconductive properities.

The authors postulated their idea from their different histological findings in the groups at fourteen days interval that PRF played an important role in acceleration of woven bone formation and initiation of spongy bone formation in group treated with PRF than other groups. These results 
agree with ${ }^{[5,6]}$ who stated that diabetes cause micro vascular complications and reduced blood flow also increase bone fragility. In addition, it reduces osteoblastic activity and bone mineralization.

In the current work wide obvious histological differences were seen at thirty days intervals in the three groups.

In the normal control group, small remnant of blood clot was seen at the surface of the defect which still replaced by area of typically organized granulation tissue with bony spicules and recruitment of osteoblasts. There was new bone characterized by thin irregular bone trabeculae. These bone trabeculae were lined by osteoblasts and harboring wide irregular marrow sinusoidal haemopiotic cavities in between them which filled with haemopiotic tissue.

On the other hand, the diabetic control group showed thin rim of well organized granulation tissues at the surface of the defect with tightly packed collagen bundles with bone spicules and recruitment of osteoblasts. Thin irregular trabeculae of woven bone were dispersed away from each other filling the center of the defect. There were wide irregular marrow sinusoidal haemopiotic cavities in between these trabeculae which filled with haemopiotic tissues. Our findings are in coincidental with the results of $^{[31]}$ who mentioned that several factors contribute to wound healing deficiencies in diabetic patients lead to impair bone healing processes. These factors include decreased angiogenic responses, collagen accumulation, changes in mineral metabolism and growth factor production. Interestingly, the diabetic group treated with PRF at thirty days interval revealed small remnant of PRF meshwork at the surface of the defect infiltrated by cells and surrounded by typically organized granulation tissues with tightly packed collagen bundles with heavy formation of bony spicules and recruitment of osteoblasts. These trabeculae were coalescent and anastomosed with each other forming bone islands and trabecular network and were connected to the old bone. There was chondroid bone formation overhanging the edge of the defect with multiple osteocytes imprisoned within its matrix. Our findings in agreement with ${ }^{[32]}$ who stated that PRF leads to superior healing of large osseous defects by entraps circulating stem cells where there is migration of stem cells differentiating into the osteoblast phenotype.

Normal control group treated with PRF at thirty days intervals showed granulation tissue surrounding small remnants of PRF with heavy formation of bony spicules and recruitment of osteoblasts. The center of the defect filled with new cancellous bone formed of thick bone trabeculae. These trabeculae anastomosed with each other forming bone islands and harboring marrow cavities filled with haemopiotic tissue. These marrow cavities become narrower as initial stage of osteon formation. There was chondroid bone formation over hanging the edge of the defect. These findings are parallel to ${ }^{[12,25,26]}$ who stated that PRF may protect its growth factors from proteolysis. Thus these factors may keep their activity over relatively longer period and stimulate bone regeneration effectively.

At sixty days interval, the surface of the defect was healed by spongy bone in the normal control group. Most likely, it was still converting to osteonal bone by narrowing of marrow cavities and forming primary and secondary osteons.

The diabetic control group, at sixty days intervals, showed that the surface of the defect was healed by cancellous bone which started to convert into osteonal bone by narrowing of the marrow cavities and formation of primary osteons in some areas. There were many reversal lines in the newly formed bone denoting active remodeling of bone. Our investigation are coincidental with the results of ${ }^{[18]}$ who recorded that diabetes is associated with bone resorption, poor osseous healing and impaired bone regeneration.

On the other hand, in the diabetic group treated with PRF at sixty days interval the defect was healed at the surface by rim of osteonal bone in different degrees of maturation which formed of primary and secondary osteons. Few islands of spongy bone were still present inside the wide marrow cavity and demonstrate formation of primary osteon. There were many reversal lines in the newly formed bone denoting active remodeling of osteon to convert to mature osteon. These results are confirmed by $^{[33]}$ who stated that many growth factors are released from PRF and the PRF can stimulate osteoblasts. In addition, PRF fibrin matrix and VEGF leads directly to angiogenesis, fibrin provides natural support for immunity and reduces inflammatory processes so PRF can improve the bone healing and remodeling.

Moreover, in the present work at sixty days intervals of the normal group treated with PRF the defect was healed by new osteonal bone characterized by formation of primary and secondary osteons. Many reversal lines denotied active remodeling of osteon to be converted to mature osteon. Marrow cavity spaces were filled with haemopiotic tissues at the center of the defect. Within these cavities there were few islands of cancellous bone still present and reveal formation of primary osteons. From the newly formed bone there were reversal lines demarcating the old one. These results are in parallel to ${ }^{[10]}$ who stated that PRF provide a matrix for migration of tissue forming cells which are involved in angiogenesis and are responsible for re-modeling of the new tissue

Many researches are also in parallel with our work in resect to the treatment of bone defect as $^{[34,35,36]}$ who postulated that PRF stimulates its environment for a significant time during remodeling by releasing many growth factors as (PDGF, TGF and VEGF) which has slower and sustained release up to 28 days. Moreover, PRF increases cell attachment, proliferation and collagen related protein expression of human osteoblasts.

We support the opinion of ${ }^{[37]}$ in that the PRF increase new bone formation and accelerated the healing of the bone defects. 
Immunohistochemical expression of VEGF revealed intense immunoreactivity in the groups treated with platelet rich fibrin than control ones. The reaction was localized in the surfaces of woven bone trabeculae, ossifying centers and wall of blood vessels ${ }^{[11]}$. postulated that VEGF is a signal protein that stimulate and angiogenesis ${ }^{[38]}$. concluded that several growth factors are expressed in distinct temporal and spatial patterns during fracture repair of these vascular endothelial growth factor which is of particular interest because of its ability to induce neovascularization. They added that VEGF is an effective therapy to promote bone repair.

\section{CONCLUSION}

The present study postulated that PRF can be used to accelerate and improve bone healing in diabetic cases.

\section{CONFLICTS OF INTEREST}

There are no conflicts of interest.

\section{REFERENCES}

1. Aaboe, M., Pinholt, E.M. and Hjorting, H.E.: Healing of experimentally created defects: Britich J. Oral Maxillofac. Surg. (1995)16:312-333.

2. Alberti, K.G.M.M. and Zimmet, P.Z.: Definition, diagnosis and classification of diabetes mellitus and its complications. Part I: Diagnosis and classification of diabetes mellitus. Report of a WHO Consultation Geneva: WHO.(1999)

3. Verhaeghe, J., Van Herck, E., Visser, W. J., Suiker, A.M., Thomasett, M. and Einhorn, T.A.: Bone and mineral metabolism in $\mathrm{BB}$ rats with long term diabetes. Decreased bone turnover and osteoporosis. Diabetes. (1990) 39:477-82.

4. Vestergaard, P.: Discrepancies in bone mineral density and fracture risk in patients with type 1 and type 2 diabetes- a metaanalysis. Osteoporos Int., (2007)18:427-44.

5. Rakel, A., Sheehy, O., Rahme, E. and LeLorier, J.: Osteoporosis among patients with type 1 and type 2 diabetes. Diabetes \& metabolism. (2008) 34:193-205.

6. Da Cunha, M. R. Gushiken, Mardegan, Issa, J. P. Iatecola, A. Pettian and Santos, M.: Osteoconductive capacity of hydroxyapatite implanted into the skull of diabetics. The Journal of Craniofacial Surgery, (2011)22:2048-2052.

7. Gabling, V. L., Açil, Y., Springer, I. N., Hubert, N. and Wiltfang, J.: Platelet rich plasma and platelet rich fibrin in human cell culture. Oral Surg.Oral Med. Oral Pathol. Oral Radiol. Endod., (2009)108(1): 48-55.

8. Choukroun, J., Adda, F., Schoeffler, C. and Vervelle, A.: An opportunity in perio-implantology: The PRF. Implantodontie, (2001) 42: 55-62.
9. Marx, R. E., Carlson, E.R., Eichstaedt, R. M., Schimmele, S.R., Strauss, J.E. and Georgeff, K.R.: Platelet rich plasma: growth factor enhancement for bone grafts. Oral Surg.Oral Med. Oral Pathol. Oral Radiol. Endod., (1998)85:638.

10. Kang, Y.H., Jeon, S.H., Park, J.Y., Chung, J.H., Choung, Y.H. and Choung, H.W.: Platelet rich fibrin is a bioscaffold and reservoir of growth factors for tissue regeneration. Tissue Eng. Part A, (2011)17:349-59.

11. Senger, D. R, Galli, S. J., Dvorak, A.M, Perruzzi, C.A, Harvey, V.S. and Dvorak, H.F.: Tumor cells secrete a vascular permeability factor that promotes accumulation of ascities fluid. Science, (1983)219:983-985.

12. Dohan, D.M., Choukroun, J., Diss, A., Dohan, S.L., Dohan, A. J. and Mouhyi, J.: Platelet rich fibrin (PRF): A second- generation platelet concentrate. Part I: Technological concepts and evaluation. Oral Surg.Oral Med. Oral Pathol. Oral Radiol. Endod., (2006)101:e37-e4

13. Carpenter, J.W.: Exotic animal formulary (4 th ed.). Philadelphia, Pa.: Saunders. (2012)

14. Plumb, D.C.: Plumb's veterinary drug hand book ( $6^{\text {th }}$ ed.). Stockholm, Wis.: Pharma Vet. (2008)

15. Drury, R.A.B. and Wallington, E.A.: Carleton's histological technique.5 th edition. Oxford University. (1980)

16. Ramos-Vara, J.A.: Technical aspects of immunohistochemistry, (2005)42: 405-426

17. Cozen, L.: Does diabetes delay fracture healing? Clinical Orthopaedics and Related Research, (1972)82:134-140.

18. Mealey, B.L.: Periodontal disease and diabetes. A two-way street. Journal of American Dental Association. (2006)137:26S-31S.

19. Galiano, R. D., Tepper, O. M., Pelo, C. R., Bhatt, k.A., Callaghan, M. and Bastidas, N.: Topical vascular endothelial growth factor accelerates diabetic wound healing through increased angiogenesis and by mobilizing and recruiting bone marrow- derived cells. Am. J. Pathol., (2004)164: 1935-47.

20. Bruder, S.P., Fink, D.J. and Caplan, A.I.: Mesenchymal stem cells in bone development, bone repair and skeletal regeneration therapy. J. cell Biochem., (1994) 56:283-294.

21. Solheim, E.: Growth factors in bone. Int. Orthop., (1998)22: 410-416.

22. Funk, J.R., Hale, J.E., Carmines, D., Gooch, H. L. and Hurwitz, S.R.: Biomechanical evaluation of early fracture healing in normal and diabetic rats. J. Orthop. Res., (2000)18:126-32. 
23. Beam, H.A., Parsons, J.R. and Lin, S.S.: The effects of blood glucose control upon fracture healing in the BB wister rat with diabetes mellitus J. Orthop. Res., (2002)20: 1210-1216.

24. Choukroun, J., Diss, A. and Simonpieri, A.: Platelet rich fibrin (PRF): A second- generation platelet concentrate. Part IV: Clinical effects on tissue healing. Oral Surgery. Oral Medicine. Oral Pathology. Oral Radiology and Endodontology, (2006 a )101(3) E56- E60.

25. Lee, J.W., Kim, S.G., Kim,J.Y., Lee,Y.C., Choi, J.Y., Dragos, R. and Rotaru, H.: Restoration of a peri-implant defect by platelet rich fibrin. Oral Surg.Oral Med. Oral Pathol. Oral Radiol., (2012) 113(4):459-63.

26. Zhang, Y., Tangl, S., Huber, C.D., Lin, Y., Qiu, L. and Rausch-Fan, X.: Effects of choukroun's platelet-rich fibrin on bone regeneration in combination with deproteinized bovine bone mineral in maxillary sinus augmentation: a histological and histomorphometric study. J. craniomaxillofac Surg. Jun., (2012) 40(4):321-8.

27. Tyndall, W.A., Beam, H.A., Zarro, C., O'Connor, J.P. and Lin, S.S.: Decreased platelet derived growth factor expression during fracture healing in diabetic animals. Clin. Orthop. Relat. Res., (2003)408:319-30.

28. Gandhi, A., Doumas, C., O'Connor, J.P., Parsons, J. R. and Lin, S. S.: The effects of local plasma rich delivery on diabetic fracture healing. Bone, (2006)38:540-546.

29. Marrellim and Tatullom: Influence of PRF in the healing of bone and gingival tissues. Clinical and histological evaluations. Eur. Rev. Med. Pharmacol. Sci., (2013) 17:1958-1962.

30. Kawamura, M. and Urist, M.R. : Human fibrin is a physiological delivery system for bone morphogenetic protein. Clinical Orthopaedics and related Research, (1988) 235: 302-310

31. Erdogan, O., Uçar, Y., Tatll, U., Sert, M., Benlidayl, M. E. and Evlice, B. A.: Clinical prospective study on alveolar bone augmentation and dental implant success in patients with type 2 diabetes. Clin. Oral Implants Res. (2014)Jul. 11.

32. Choukroun, J., Diss, A., Simonpieri, A., Girard, M.O., Schoeffler, C. and Dohan, S.L.: Platelet rich fibrin (PRF): A second- generation platelet concentrate. Part V: Histologic evaluations of PRF effects on bone allograft maturation in sinus lift. Oral Surg.Oral Med. Oral Pathol. Oral Radiol. Endod., (2006 b )101:299-303.

33. Jiing-Huei, Chung-Hung, Tsai and Yu-Chao Chang: Clinical and histologic evaluations of healing in an extraction socket filled with platelet rich fibrin. J. dental science, (2011)6:116-22.

34. Mazor, Z., Horowitz, R.A., Del Corso, M., Prasad, H. S., Rohrer, M.D. and Dohan Ehrenfest, D.M.: Sinus floor augmentation with simultaneous implant placement using Choukroun's platelet rich fibrin as the sole grafting material: A radiologic and histologic study at 6 months. J. Periodontol, (2009)80: 2056-2064.

35. Tsai, C.H., Shen, S.Y., Zhao, J. H. and Chang, Y.C. : Platelet rich fibrin modulates cell proliferation of human periodontally related cells invitro. J. Dent. Sci., (2009) 4:130e5.

36. Wu, C.L., Lee, S.S., Tsai, C.H., Lu, K.H., Zhao, J.H. and Chang, Y.C.: Platelet rich fibrin increases cell attachment, proliferation and collagen related protein expression of human osteoblasts. Aust. Dent. J., (2012)57:207-12.

37. Kökdere, N.N., Baykul, T. and Findik, Y.: The use of platelet-rich fibrin (PRF) and PRFmixed particulated autogenous bone graft in the treatment of bone defects: An experimental and histomorphometrical study. Dental Research Journal, (2015) 12 (5):418-424

38. Street, J., Bao, M., deGuzman, L., et al: Vascular endothelial growth factor stimulates bone repair by promoting angiogenesis and bone turnover. Proc. Nati. Acad. Sci. USA, (2002)99(15):9656-61. 
الملخص العربى

\title{
تقييم تأثثر الليفين الغتى بالصفائح الدموية على إلتئام التجاويف العظمية فى عظمة قصبة الساق فى الفئران المصابة بالسكرى (دراسة هستولوجية وهستوكيميائية مناعية)
}

\author{
محمد عبد السلام السخاوى'، هانى شريف'، عبد الناصر عبد المولى اسماعيل'، دينا وجيه محمد بشير'

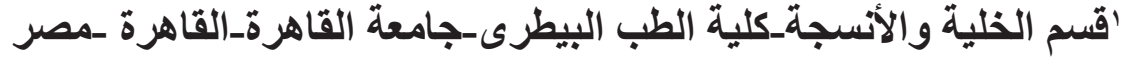

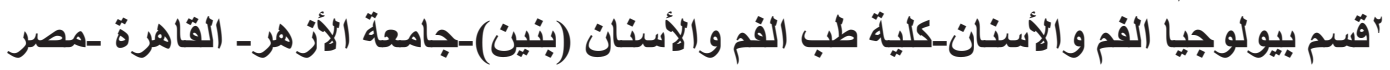

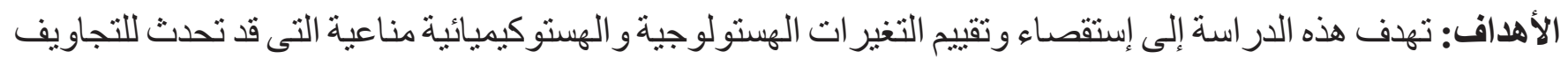

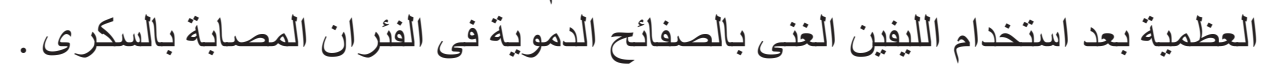

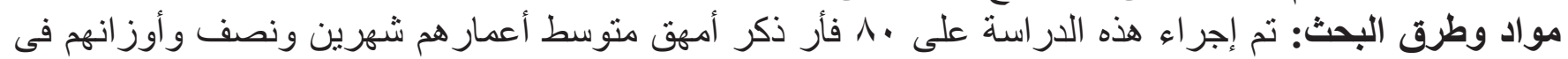

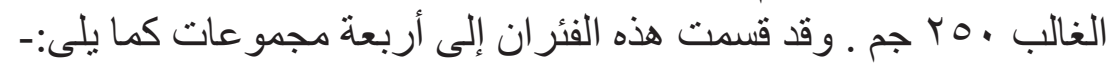

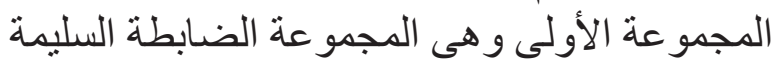

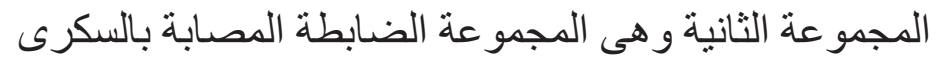

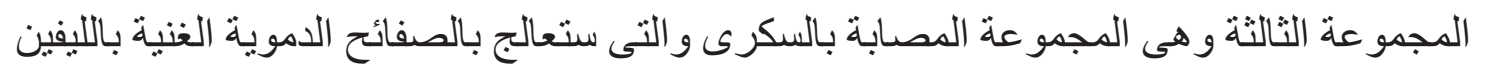

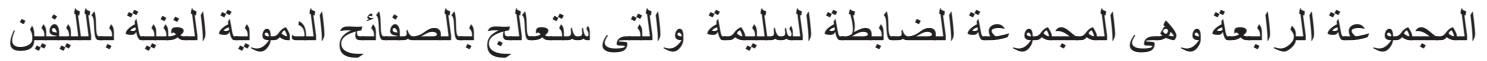

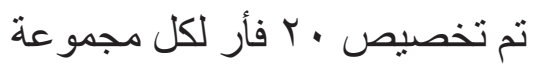
تم تقسيم كل مجمو عة إلى أربعة فترات زمنية مختلفة ـ الفترة الأولى لمدة سبعة أيام والفترة الثانية أربعة عشر يوما

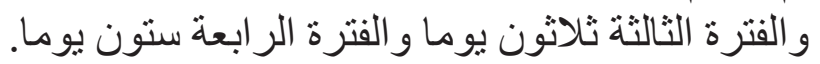

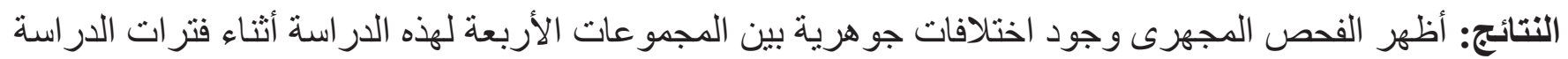

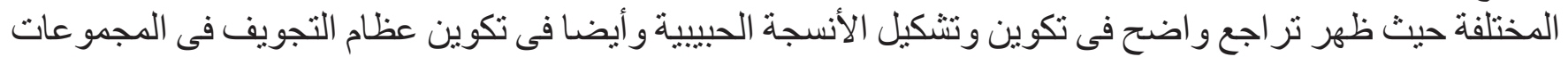

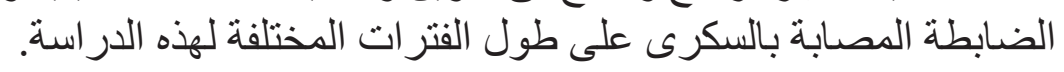

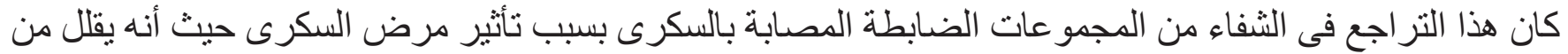

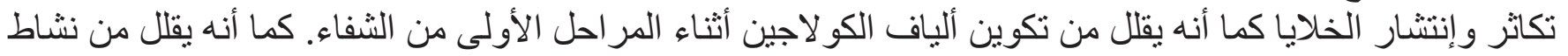

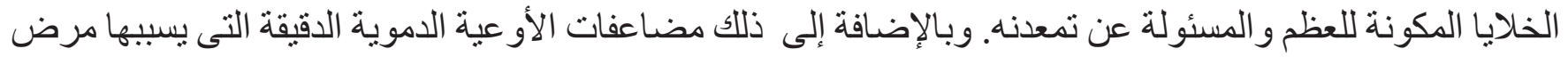

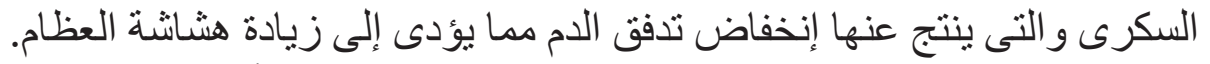

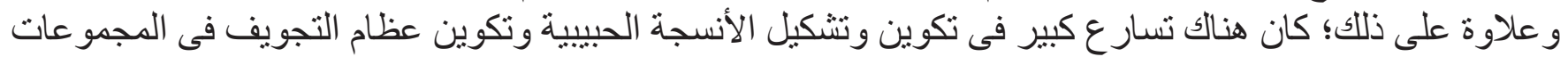

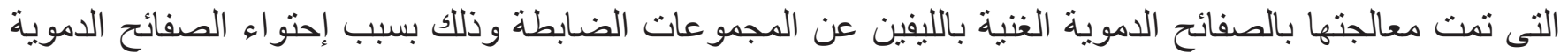

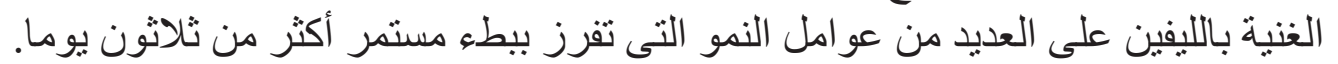

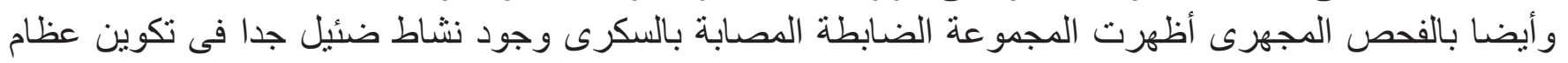

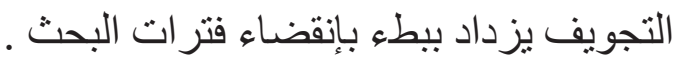

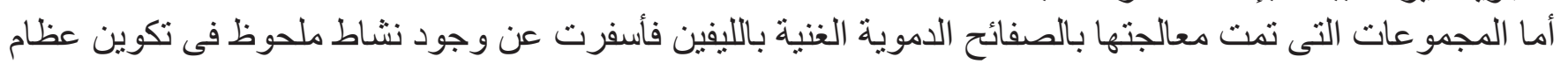

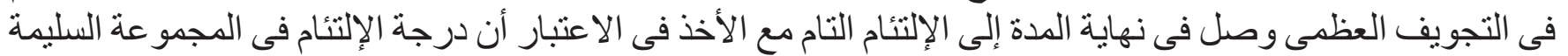

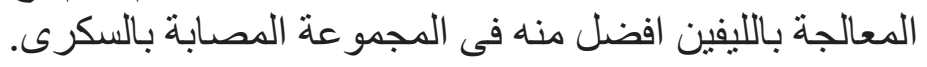
وقد أظهر تفاعل عامل نمو الخلايا البطانية المناعى نشاط كثيفا فى المجمو عات التى تمت معالجنها بالصفائح الدموية الغنية بالليفين الاستنتاج: مما سبق، يتضح أنه من الممكن استخدام الصفائح الدموية الغنية باللافين لتسريع وتحسين التئام العظام في حالات مرضى السكري. 